\title{
Transition to marriage and parenthood among youth in Bihar
}

International Institute for Population Sciences (IIPS)

Population Council

Follow this and additional works at: https://knowledgecommons.popcouncil.org/departments_sbsr-pgy

Part of the Demography, Population, and Ecology Commons, Family, Life Course, and Society Commons, International Public Health Commons, and the Medicine and Health Commons How does access to this work benefit you? Let us know!

\section{Recommended Citation}

International Institute for Population Sciences (IIPS) and Population Council. 2009. "Transition to marriage and parenthood among youth in Bihar," Youth in India: Situation and Needs Policy Brief no. 18. Mumbai: IIPS. 


\section{Transition to marriage and parenthood among youth in Bihar}

Delaying the transition to marriage and parenthood among young people has been a policy and programme priority for several years in India. For example, several national level policies formulated since 2000, including the National Population Policy 2000, ${ }^{\mathrm{a}}$ the National Youth Policy $2003^{\mathrm{b}}$ and the National Adolescent Reproductive and Sexual Health Strategy ${ }^{c}$ have advocated special programme attention to delay age at marriage and age at first birth.

Despite these commitments, substantial proportions of girls continue to marry in adolescence. As recently as in 2005-2006, more than two-fifths (47\%) of women aged 20-24 were married by 18 years nationally. ${ }^{\mathrm{d}}$ Likewise, over one-fifth (22\%) of women aged 20-24 had given birth before age 18 and two-fifths (42\%) before age 20 . While the magnitude of early marriage and childbearing has been widely documented, far less is known about the extent to which young people are involved in planning their marriage, how prepared they are for married life and the nature of their married life.

This policy brief documents the magnitude of early marriage and early childbearing in Bihar and sheds light on young people's involvement in marriagerelated planning and preparedness for married life, and the nature of married life.

The study

Data are drawn from the Youth in India: Situation and Needs study, a sub-nationally representative study undertaken for the first time in India of key transitions experienced by young people in six states of India. The study included a representative survey of young people in both rural and urban settings. Respondents included unmarried women and men and married women aged 15-24 and, in view of the paucity of married men in these ages, married men aged 15-29.
In Bihar, the survey was conducted in 2007. A total of 8,136 married and unmarried young men and women were interviewed in the survey. These included 1,115 married young men, 1,492 unmarried young men, 2,341 married young women and 3,188 unmarried young women. This brief is based on data obtained from the sample of married young men and women.

Child marriage continues to mark the lives of young women and men

Youth Study findings underscore that child marriage continues to characterise the lives of young women and men in the state. Of those aged 20-24, almost half of young women $(46 \%)$ were married before age 15 , more than three-quarters $(77 \%)$ before age 18 and almost nine in ten $(87 \%)$ before age 20 . Young women in rural areas were almost three times as likely as urban young women to be married before age 15 (50\% compared to $17 \%$ ) and almost twice as likely to be married before age 18 ( $82 \%$ compared to $45 \%)$.

Even though early marriage was less prevalent among young men than young women, one in $8(13 \%)$ young men aged 20-24 years was married before age 18 and almost one-third (31\%) before age 20. In rural areas, as many as one in seven and one in three young men was married before age 18 and 20, respectively. Indeed, more than two-fifths of young men aged 21-24 $(43 \%)$ were married before the legal minimum age at marriage of 21 , ranging from $20 \%$ of those in urban areas to $47 \%$ of those in rural areas.

Of note is the striking difference in the proportion of young people married before the legal minimum age at marriage by years of schooling completed by young women and men. Over nine in ten young women with no formal schooling were married before age 18. The proportion of young women married before

Age at marriage: percentage of young women and men aged 20-24 who were married before selected ages

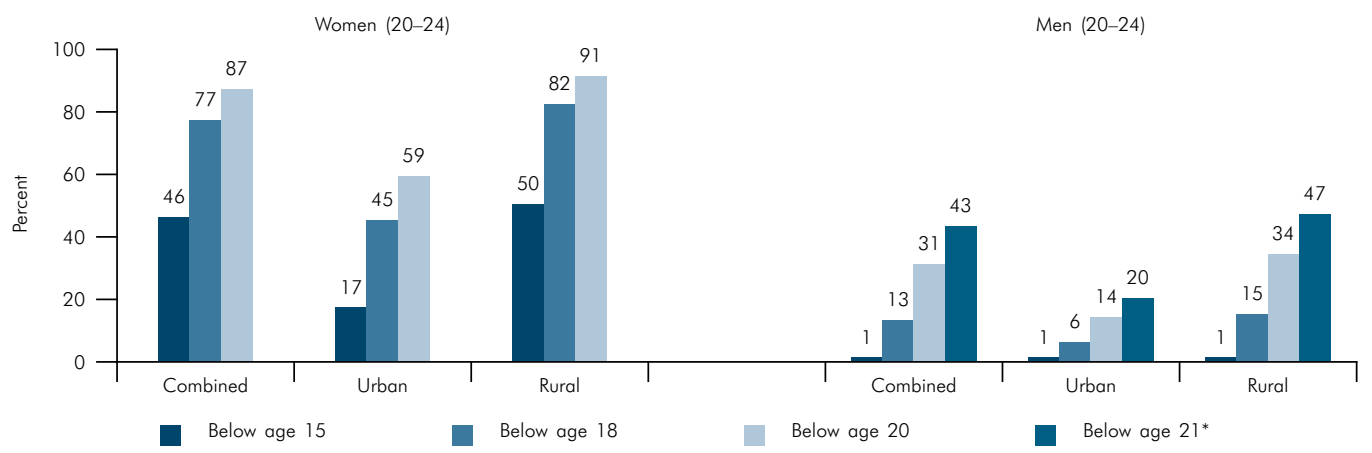

*Among those aged $21-24$.

\footnotetext{
${ }^{a}$ Ministry of Health and Family Welfare. 2000. National Population Policy 2000. New Delhi: Government of India.

b Ministry of Youth Affairs and Sports. 2003. National Youth Policy 2003. New Delhi: Government of India.

${ }^{c}$ Ministry of Health and Family Welfare. 2006. Implementation Guide on RCH II: Adolescent Reproductive Sexual Health Strategy for State and District Programme Managers. New Delhi: Government of India.

d International Institute for Population Sciences (IIPS) and Macro International. 2007. National Family Health Survey (NFHS-3), 2005-06: India, Volume 1. Mumbai: IIPS.
} 
Percentage of young women aged 20-24 who were married before the legal minimum age at marriage, according to years of schooling, religion and caste

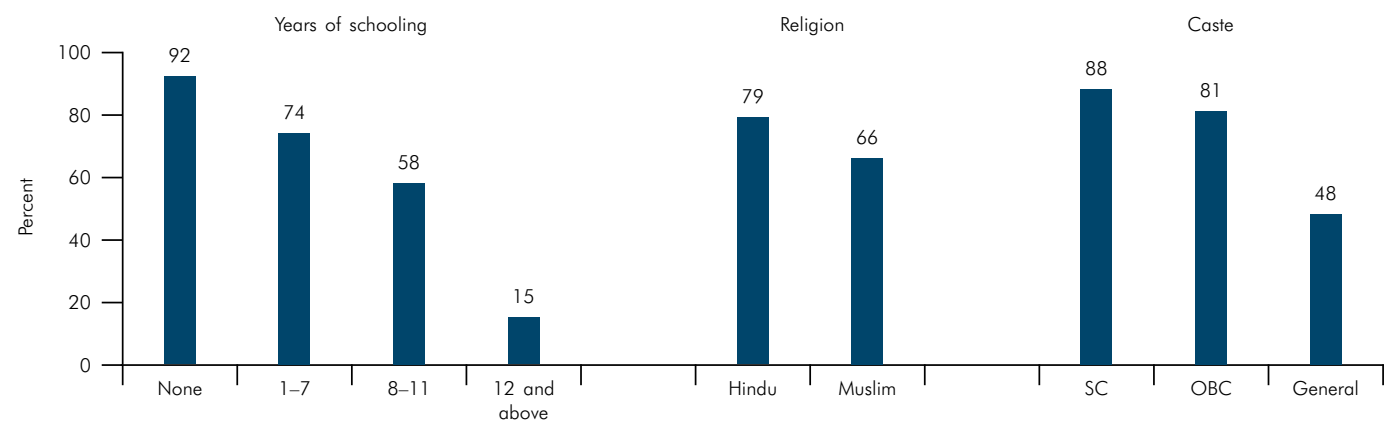

Percentage of young men aged 21-24 who were married before the legal minimum age at marriage, according to years of schooling, religion and caste

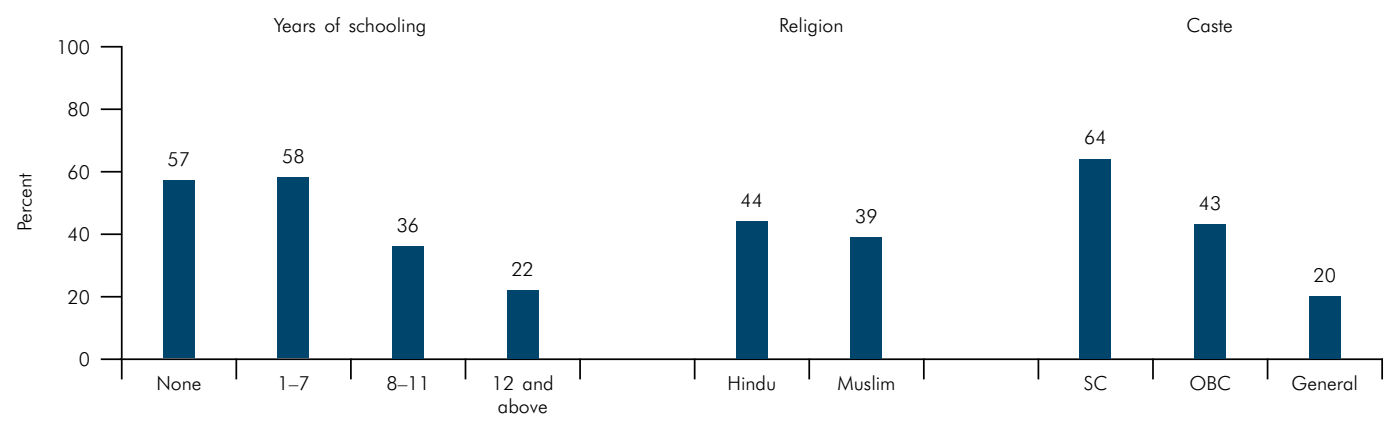

the legal age declined to $58 \%$ among those who had some secondary education and $15 \%$ among those who had completed at least 12 years of schooling. Among young men, the proportion marrying before the legal age declined from $57-58 \%$ among those with no formal schooling or 1-7 years of schooling to $22 \%$ among those who had completed at least 12 years of schooling. Also evident are differences by religion and caste. Almost four in five Hindu women had married before the legal age, compared with two-thirds of Muslim women. Differences by religion are mild among young men. Caste-wise differences suggest that young women and men belonging to general castes were much less likely than others to have married before the legal age.

Young people are rarely consulted in planning their marriage

Although marriage is a key marker of young people's transition to adulthood, Youth Study findings highlight that young people were rarely consulted in planning their marriage. Just over one in five married young men $(21 \%)$ and about one in 20 married young women $(4 \%)$ reported that their parents had consulted them on the timing of their marriage.

With respect to selection of spouse too, young people's involvement was limited. Almost all youth (99\%), whether male or female, had married a partner chosen by their parents. While almost nine in ten married young men $(88 \%)$ reported that their parents had sought their approval while determining their wifeto-be, young women fared much worse; fewer than three in five married young women $(56 \%)$ reported that their parents had sought their approval while determining their husband-to-be so. Indeed, one in ten young men $(11 \%)$ and more than two in five young
Young people's involvement in planning their marriage

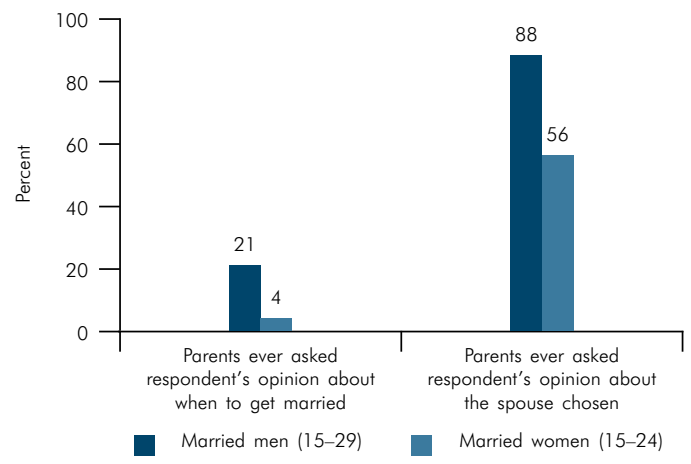

women $(43 \%)$ reported that their parents had not sought their approval at all.

Few young people have opportunities to get to know their spouse-to-be before marriage

Just $7 \%$ and $4 \%$ of married young men and women, respectively, reported that they had ever had a chance to meet and interact with their spouse-to-be alone prior to marriage. Indeed, more than nine in ten youth (91-94\%) reported that they had met their spouse for the first time on the wedding day. Moreover, just two in five young men $(37 \%)$ and one in five young women (19\%) reported that they were aware at the time of their marriage of what to expect of married life.

Communication between spouses is limited Findings suggest that spousal communication, even on such topics as spending money, number of children they would like to have and contraception, was not universal. In total, $86-88 \%$ reported regularly discussing how to spend money and $78-84 \%$ reported
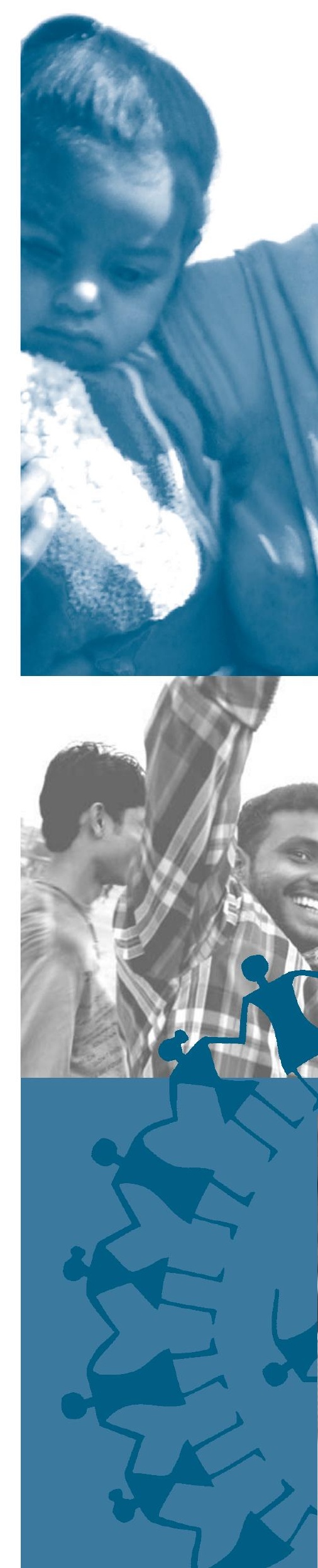
Spousal communication: percentage of married young men and women who discussed various issues with their spouse

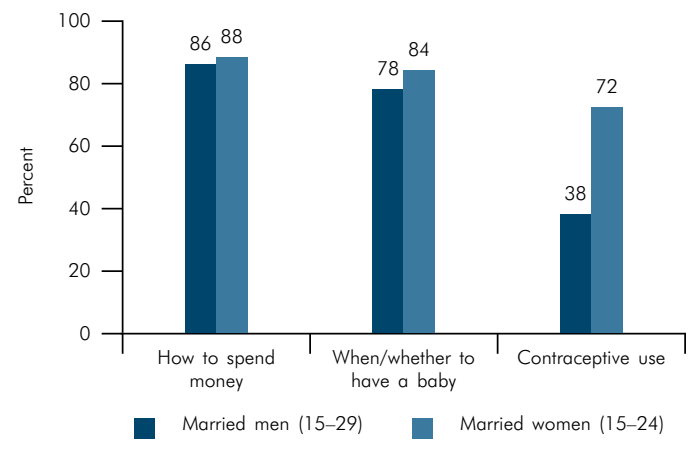

having discussed whether and when to have a baby. Discussion was somewhat more limited on the topic of contraception, and notably, fewer young men $(38 \%)$ than women $(72 \%)$ reported that they had ever discussed contraception with their spouse.

Marital life is marked by considerable violence Findings highlight that marital life was marked by considerable violence, both physical and sexual. As many as $30 \%$ of married young women reported the experience of some form of physical violence within marriage. A similar proportion of married young men reported the perpetration of physical violence on their wife. For almost one-tenth of married young women, the experience of physical violence took place within the first year of marriage itself, and a similar proportion of married young men reported perpetrating physical violence within the first year of marriage.

Violence within marriage: percentage of young women who experienced violence perpetrated by their husband

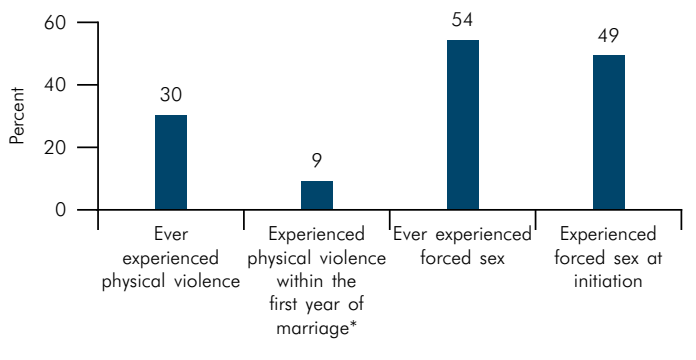

*Of those who had cohabited with their husband for at least 12 months

Violence within marriage: percentage of young men who perpetrated violence on their wife

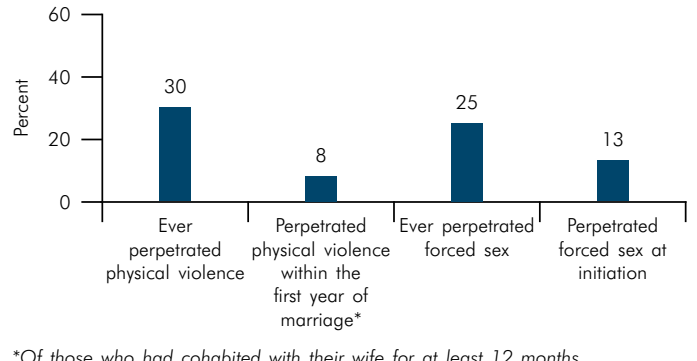

Far more young women reported having experienced sexual violence than physical violence within marriage. Over the course of their marital lives, more than half of young women reported the experience of forced sex within marriage. In contrast, one-quarter of young men reported that they had ever perpetrated forced sex within marriage. Forced experience at sexual initiation itself was reported by almost half of young women; in comparison, $13 \%$ of young men reported that they had forced their wife to engage in sex the first time.

Contraceptive use within marriage is limited Youth Study findings indicate that the practice of contraception at any time during marital life was limited among young people in the state. Just $20-23 \%$ of young men and women reported ever use of contraceptive methods, and at the time of interview, just $12 \%$ of both young men and women were doing so. Findings, moreover, indicate that the practice of contraception to delay the first pregnancy was almost non-existent; reported by only $8 \%$ of young men and $4 \%$ of young women.

\section{Contraceptive practices: percentage of married young men and women who reported use of contraceptive methods}

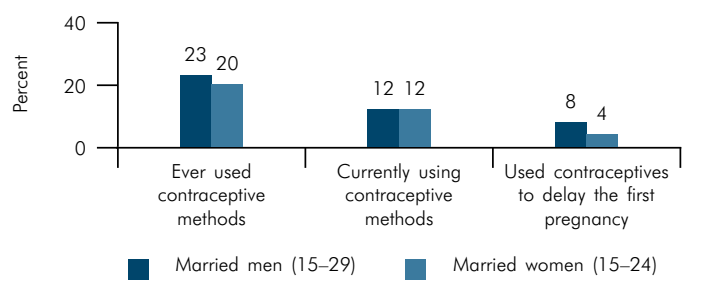

Given that few young people had practiced contraception, it is not surprising that almost one in four young men whose wife had ever became pregnant $(23 \%)$ and one in three young women who had ever became pregnant $(33 \%)$ reported that their last pregnancy was mistimed or unwanted.

Childbearing in adolescence is extremely common The pressure to prove fertility as soon as possible after marriage is experienced by considerable proportions of married youth. For example among young men and women who had cohabited for 12 months or more and for whom age at first pregnancy was known, one-third $(33 \%)$ of young women and some what more $(37 \%)$ young men reported that the first pregnancy occurred within six months of marriage, and $57 \%$ of young women and $61 \%$ of young men reported that it occurred within a year of marriage.

Findings, moreover, highlight that childbearing in adolescence is extremely common in the state. A substantial proportion of young women had their first pregnancy at a young age. Among married young women aged 18 or above who were cohabiting with their husband at the time of the interview, two-thirds $(68 \%)$ as had their first pregnancy before age 18 . Among married young men who were cohabiting with their wife and whose wife was aged 18 or above, $44 \%$ reported that their wife had her first pregnancy before age 18 . 
Early childbearing: percentage of married young men and women reporting first pregnancy within a year of marriage and by age 18

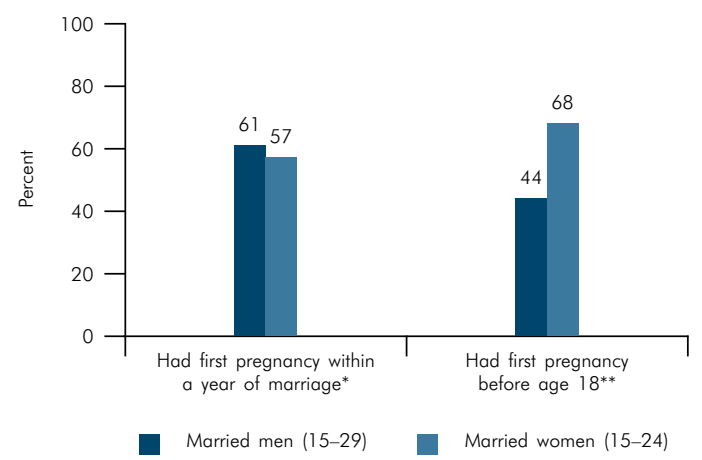

*Among those who had cohabitated with their spouse for 12 months or more. ${ }^{* *}$ Among young women and young men whose wife was aged 18 or above and were cohabiting with their spouse at the time of the interview.

Utilisation of maternal health services is limited Findings suggest that despite the early age at first pregnancy, utilisation of maternal health services by young women was limited. For example, just 23-25\% of youth reported that the first-often the most risky-delivery took place in a health care facility. Although the situation was far better in urban than rural areas, just half $(51 \%)$ of young women in urban areas had experienced their first delivery in a health facility and two in five (40\%) young men reported that their wife's first delivery had taken place in a health facility. Skilled attendance at first delivery was also limited, reported by just $42 \%$ of young men and $35 \%$ of young women of youth.

\section{Programme recommendations}

Findings call for multi-pronged efforts to eliminate the practice of early marriage and support newly-wed young women.

\section{Mobilise communities to eliminate the practice of early marriage}

Strategies are needed that mobilise communities to help parents resist pressures that foster the practice of early marriage, and to establish new norms and practices with regard to marriage. Community mobilisation efforts must involve youth themselves, their families, as well as influential persons in the community, including religious and political leaders.

\section{Enforce existing laws on the age at marriage and the} registration of marriages

Equally important is to ensure greater commitment on the part of law enforcement agencies to enforce existing laws on the minimum age at marriage and the registration of marriages, and to levy penalties on violators. Allowing anonymous reporting, making law enforcement agencies and others aware that the practice of early marriage is not a minor violation, and making the guidelines for penalties clear to enforcement agencies and the wider community are possible steps in this direction.
Provide girls with viable alternatives to early marriage

Efforts to delay marriage also require providing girls with viable alternatives to early marriage in the form of accessible and quality schooling, and opportunities to build and use livelihood skills. Working with the education sector to make schooling for girls more accessible, and to make classrooms gender-sensitive and responsive to the needs of girls and the concerns of their parents is important. At the same time, it is necessary to provide livelihood training within and outside the educational system and to provide those out-of-school a second chance at education.

\section{Work with parents}

Parents must be apprised of the need to involve children in marriage-related decisions and enable them to interact with their prospective spouse prior to the wedding day. Parents must also be made aware of the fact that early marriage compromises young women's lives and reproductive health and choices in multiple ways.

Support newly-weds to postpone the first pregnancy and promote pregnancy-related care among first-time pregnant young women

Programmes are needed that inform youth about their pregnancy postponement options and enable them to access appropriate contraception. At the same time, providers must be trained and given the responsibility of reaching married young women and men-including those who have not yet experienced pregnancy-with information regarding contraception and other reproductive health matters as well as contraceptive supplies.

Findings, moreover, highlight that reproductive and child health programmes in the state need to build a demand for, as well as improve the availability of, maternal health services among young people.

\section{Address the social vulnerability of newly-wed young} women

Findings on the multiple vulnerabilities faced by young women who were married early underscore the need for programmes that support newly-wed young women, acknowledging that their situation and needs may differ from those of married adults. Efforts are needed that address the empowerment needs of married young women, enable young women to have greater control over resources, break down the social isolation they experience and encourage couple communication, negotiation and conflict management skills early in marriage.

There exist many policies and programmes-be they related to women and child development, youth or health and family welfare-that have recognised the importance of preventing early marriage and improving sexual and reproductive health and choice among young people, and that have widely acknowledged the special vulnerabilities of young women. What is needed now is ensuring that programmes in Bihar do indeed reach young people and the influential adults in their lives, and that promising lessons are assimilated and scaled up. 